\title{
Sustainable Management: New Insights
}

\author{
Sujata Dhopte ${ }^{1 *}$ and Meena Sinha ${ }^{2}$ \\ ${ }^{1} \mathrm{M}$ K Sanghvi College of Commerce and Economics, Mumbai, Maharashtra, India \\ ${ }^{2}$ Research Scholar, Pacific University (PAHER), Udaipur, India
}

\section{Abstract}

Sustainable value framework can be created by building enhanced utility and greater profitability. Big corporations can ensure excellence not only by building quality in products but also by standardising the processes through training their people. Highly skilled global workforce is the solution to our planet where we are looking for global economy. Resource optimization - both in natural and human would help us sustain this planet. This paper examines the current thinking on the processes of corporate learning systems and explores the issues of sustainability in learning. New research shows how the big corporations in the globalised world can achieve sustainable results by adopting new corporate philosophy which requires re-structuring around human workforce's continuous and time-bound learning in organizations.

\section{Keywords: Sustainability, Corporate Learning Systems, Human Capital, Value-based Profitability}

\section{Introduction}

A new global business world faces challenges like economy which is knowledge based, globalization and technological evolution. This has led many organizations and countries to look for new ways to keep reasonable advantage. The existing understanding is that success people who have higher levels of individual competence. Towards the end, people are being perceived to be treasured assets and they can be acknowledged within a framework of human capital. In the economic viewpoint, along with the capital meaning, the subject is human who will take charge of all activities related to economic like production, transaction and consumption. Once these concepts are established, it can be documented that human capital is one of the added value - generating production elements.

\subsection{Rationale}

Today's economy has become a global economy as it has ceased to be economy of this or that nation. Continents and nations are derived by waters but beneath the ocean, land mass unifies them. Geographical divisions based on political concepts are man-made. Nature unifies and this applies to global economy of which global trades \& global finances are integral parts.

In 2000, it was: Think local, do local, and go global. In 2010, it became: Think local, do local, let the globe come to you (Global Village). In 2050, 30 crores will be out of India.

1. By 2050, there are going to be $500 \mathrm{MNC}$ and TNCs globally and India is going to be largest next to America. 2. 30\% of Indian population is going to be technically busy globally. $65-70 \%$ population would be busy with operations in business in India and the developed countries. 3 . There is going to be more automotive and manufacturing of Robotics.

\section{Examples of the expected changes:}

1. The proposed Vedanta University : It is going to be the biggest. 2. Indian Railways: It will give best metro 
system without prioritizing. We already have trains in India in a few places with high speed like Delhi, Agra, Jaipur/Chennai, Bangalore/Mumbai - Delhi. The changes to make it magnetic will require more manpower. We already have 1.5 million workers today in Indian Railways at par with 1.8 at Wal-Mart of US. 3. ITC: It is an MNC not confined to only India 4. Mahindra: Bus, Trucks, 2-Wheelers, SUVs, Cars, Aircrafts.

'Hard Skills' demands are going to rise in context of Software applications, Mission usage, Waste elimination, Productivity enhancement, Continuation of quality growth and meeting market demands for value for money. Corporate Skills of current century have evolved as dynamic trends of learning, application and utility for modern management with contemporary validity of content and orientations. Corporate Skills industry comes first and management academic next. In the growth process, corporate skills have incorporated the concept of Soft Skills and Hard Skills which are merged for the delivery for practical business orientations. That's why the industry has concentration for 'Role Orientation' rather than the earlier 'Goal Orientation' of the twentieth century.

The workforce demands proper training of skills as there is skills gap. For the economy to be sustainable, human capital needs to be created as the focus. So far the focus has been only on customer and not on employee.

\subsection{Objective of the Study}

To examine the current practices in corporate learning systems and their role in corporations' sustainable future.

\subsection{The Focus of the Study}

This particular research proposes to provide a better appreciation of the management and leadership skills required in global corporations, identify international best practices in the use of corporate skills, latest trends in knowledge management and human capital management and links between training, learning and business performance in leading-edge companies to senior managers and executives of MNCs.

This research will be able to provide a better understanding of the corporate skills requirement of MNCs, their ways in which these are transforming in the context of the global economy, mark the best practices utilized to help MNCs acquire the appropriate corporate skills and also identify ways in which MNCs can enhance the skill levels in local and national workforce market to the policy-makers.

\subsection{Research Methodology}

This study is based on the data, which is secondary and research is conceptual in nature and descriptive. Essentially, the necessary information has been acquired from: 1 . several books 2 . many articles from journals, magazines and newspapers 3 . few websites which deal straight or in some way with the keywords. The objective of present study is addressed after the relevant information is collected and examined.

\subsection{Limitations of the Study}

The study is built on published facts and information. No primary data has been collected. Secondary data may lack in accuracy or may not be completely dependable. The biasness can always be there. Before using secondary data, it is important to evaluate it; so it consumes the same time as the primary data.

\section{Trends}

\subsection{Changing Corporations in the New Business World}

Globalization has changed the fundamental model of businesses. Corporations are shaping new strategies, managing and operating in a truly global way, generating the capacity to bring together and set up global capabilities more rapidly, more resourcefully and successfully. These globally integrated enterprises locate jobs and tasks anywhere across the world based on the right cost, skills, and business environment and integrate processes worldwide horizontally. Right now, the shift is from the product orientation to customer orientation. Soon it is going to be employee oriented. 
Kohli (2012) believed "In the developing global order, business leadership is a whole new standard. The previous challenges like access to technology which is limited and access which is limited to global resources such as talent, capital, and natural resources have given way to a world without boundaries. Companies are now operating in different geographies and industries and are confronted with a fresh set of challenges that mainly emerge from the competitive global business regime, alongside the call for sustainable development".

Evolution of transnational corporations and the emerging markets brought in the new world order. From Market seeking to resource seeking, they have now become efficiency seeking. MNCs and TNCs of other countries now operate through required Corporate Skills Learning as per the local and regional environment and culture. They operate through understanding Indian consumer behaviour and then they market their entry strategies. They have commitment at the global level while remaining focused on their long term objectives.

\subsection{Corporate Re-structuring}

Economic influence is shifting from U. S. and Europe, to Asia and many organizations from developing nations are in a worldwide race to the top but the position will be won by only those multi-national companies which are committed to partnership and by individuals who are committed to continuous, life-long, enhanced learning and to education.

Although this new globalized setting requires improved technical and logistical skills, the chief obstacle to success is attitude. We believed in 'Customer First' earlier but now we need to look at 'Employee First' to be able to serve customer better. The new philosophy orientation requires more of role-relationship than a goal-oriented one.

When population and economies grow, they create challenges of scarce resources and issues of sustainability. China, by 2035, will use third of all global energy provided by renewable energy sources. New rules have emerged for the companies and individuals.
The requirement is to shift from land, labour and capital to knowledge shared by humans.

In Europe, working population is going to fall. So the new workforce will have to be created and there will be migration from the developing countries. People will have to be trained with right skills to take the bright opportunities. For India, to become developed economy in 2050 educational policies need to be changed at primary, secondary and tertiary sectors. Even at the corporate sector, government and NGOs have to go hand in hand. In this new corporate led globalised world, MNCs have got lot of power, creating global economy where all the economies of the world are integrated like uninhibited trade and finance, flows, mutual exchange of knowledge and technology and movement of labour.

When the philosophy was "Think local, Do Local \& Go Global", knowledge building alone was alright but now with the new one, "Think Local, Do Local, Let the Globe Come to You", lots of job opportunities are created. By 2030, there will be lots of migration in the workforce.

\subsection{Learning Organisations}

Learning organizations try to cognize how individuals and organisations learn, and in the process, they facilitate the process of attaining and applying newly acquired knowledge. They cultivate a culture where individual development becomes a main concern and individuals get enabled, motivated, and they become passionate about sharing their knowledge.

The characteristic of an adaptive organization is learning, i.e. an organization that is able to feel changes in its environment both internally and externally and adapt accordingly.

For every organization or a company to survive, knowledge management is a foundation. It helps organizations to grow with continuous improvement while adapting with the changing business environment. The top management in a company needs to clearly understand the concept of knowledge management as a sharing knowledge. The good sharing knowledge in 
a company may enable people in organization to create innovation. This sharing and making knowledge in organization enables a company to stay ahead in the changing market environment.

Capkovic (2012) believes "Development of foundational competencies and lifelong learning becomes one of top priorities for modern multinational corporations in constantly changing market and economic circumstances".

What we need is knowledge-driven learning models for a competitive advantage in the industry.

\subsubsection{Understanding the Organizational Learning Process from Inside Out: New Paradigm}

The main challenge for all is sustainability. It is the branding central, from inside out. The issues related to strategic approaches, practices, persons, organisational structure and rewards should be addressed by internal communication process. HR strategies for the development of employees need to be carefully linked and incorporated with the business, corporate, and functional schemes of the organization to achieve sustainability. The management at the top will have to work carefully with all managerial levels. Soft skills, as important as hard skills, have to play a prime role in this. Singh (2013) describes "The internal knowledge can be leveraged for competitive advantage by taking measures to bridge the gap between managerial hierarchies. Value creators will have to motivate employees instead of just being workers for the organization. This calls for clear communication between all ranks of the management. Only HR people can bring sustainability by providing the workforce with opportunities for sharing and learning in teams. They can embed sustainability in the organization's culture to realize its true value".

\section{Strategies}

\subsection{The Issue of Sustainability}

We need to establish a new or higher order organization for sustainability development. Sustainability is a long run and people-centred concept. Development of resources like natural, human, and economic needs to be sustained as the developmental purpose which is a positive change in human progress and not necessarily numerical growth.

"Sustainability encompasses three levels: the individual, the organizational and the societal." Docherty et al. (2002). As per Cavagnaro and Curiel (2012), "Sustainability at one level cannot be built on the exploitation of the others. The ultimate goal of sustainable development is securing better quality of life for all, both now and for future generations, by pursuing responsible economic growth, equitable social progress, and effective environmental protection." He says it at the societal level. According to Elkington (2006) and Wikstrom (2010), "Triple Bottom Line model is based on social, environmental and economic outcomes. It is grounded in the systems theory and postulates that sustainable development can be achieved only when there is a balanced and equal attention to all three main elements of the system".

Porter (1998) uses the word "Sustainability to describe sustainable competitive advantage of organizations". As per the resource-based theory by Barney (1991), "The key sources of long-term, sustainable competitive advantage are human resources, knowledge and intellectual capital".

Rising competition poses a threat to organisations' extended survival and sustainability is a major issue to them. The triple bottom line of sustainability is formed by people, planet and profit. However, five elements like strategy, processes, people, structure and rewards have to be closely integrated with sustainability initiatives to gain competitive advantage.

According to Singh (2013), "Sustainability cannot be achieved only externally. What the organization gives to its workforce as internal payback is more crucial for meeting the challenges of sustainability. The employees and the work environment have a direct impact on employer branding. An organization that creates a kind of brand image to the outside world can only make it the best place to work in. It is important to 
take care of the internal communication flows and total development of the employees in the organization for gaining employer branding".

Terry (2012) explains, “Today, sustainability is such common currency in the business world that $93 \%$ of chief executives around the globe view it as 'critical to the future success of their companies'. Growing numbers of companies around the globe are striving to radically change their business models".

\subsubsection{Human Capital Sustainability}

Jacobs and Slaus (2011) describe, "The development of human capital over time is a function of the quantity and quality of human capital (which includes all forms of social capital as well), natural capital (e.g., ecosystem, air, water) and human-made capital (e.g., money, infrastructure, building, and roads) and their evolution. Though resources exist outside and independent of human beings, they are recognized as resources only by human beings. Knowledge is a resource, that exists only within human beings. Human capital, natural and human-made capitals are interconnected".

According to Schumacher as cited in Ardichvili (2012), "Highly educated human resources are the most important assets of any organization or society. Education in modern societies and training and development in industry is mostly about acquiring more knowledge. Such emphasis on expanding the knowledge pool makes sense in conditions of perpetual economic growth. However, sustainable societies need education and HRD that focus on different priorities. Under the new paradigm, education and development need to focus on expanding human capacity for moral reasoning and compassion".

Valine Jerotich Koech Bartocho (2016) says, "Conceptual foundation of one's human capital is based on knowledge and a skill acquired by an individual's learning activities. Knowledge can broadly include other factors of human capital such as skills, experience, competency and human capital. Such accumulation of human capital through learning activities significantly influences many sectors".

\subsection{Use of Training for Facilitating Sustainability Learning in Corporations}

\subsubsection{Learning Systems of Skills}

Governments all over the world, realise that the first step towards achieving high-value, high-skill economies is to have a well-educated workforce. According to Vince Cable (2011), "As our country strives to strengthen economic growth and create the jobs that will come with it, businesses of all sizes are crying out for people with the right skills to design, produce and sell a quality product efficiently. The future of thousands of communities all over the land depends on whether or not those skills will be available. So, do the futures of millions of people, especially young people. The new vision for skills would require businesses to continue to invest in training of skills of their workforce while continuing to recognise several key areas". Research and design which are high end activities do not have to go on in the high-cost economies of Europe, North America or Japan as used to be thought earlier by leading corporations. Now new ways are being developed by them to standardise high-value work as manual work.

ILO (2010) reports that "Route to economic prosperity, reduced income inequalities and social cohesion is through creation of world-class skills. While many corporations invest heavily in ongoing education and skills training of employees, they still depend on the solid foundation taught during primary, secondary, and tertiary education. Their sustainability depends on the innovation and expertise of their employees. That's why their priority will always be the recruitment and retention of top talent".

APEC (2010) strongly believes that "New knowledge and skills are required for the workforce in the global economy. In culturally diverse societies, employees need to work productively and communicate effectively across international boundaries. Workers in multinational corporations must be able to speak and write in foreign languages, demonstrate knowledge of world issues, and use a broad range of new technology in unprecedented ways. These broad skills represent a few of the 21 st century competencies that many APEC 
member economies have been defining and integrating into educational systems".

\subsubsection{Skill Development}

FICCI (2012) report says, "The gap exists between what business needs and what education provides. There is a need to change corporate perspectives. So we have new chances for the skills system reform plan and implementations. One should rethink of globalization as a guiding paradigm for systemic education change. It is clear that skill development has been largely ignored in our country and is one of its major needs. India's workforce will be younger than the workforces in many global economies but skill development is critical if we are to take advantage of this demographic edge. It is expected that the ageing-economy phenomenon will globally create a skilled manpower shortage of approximately 56.5 million by 2020".

A Mckinsey Report (2012) reveals "Global Institute survey reveals that multinationals find only $25 \%$ of Indian engineers employable. Similarly, according to a New York Times report, only one in four engineering graduates in India is employable, based on technical skills, English fluency, teamwork and presentation skills. This kind of shortage is evident in other streams as well. If the trend continues, the National Association of Software and Service Companies (Nasscom) projects a shortage of 500,000 knowledge workers by 2010; the BPO service sector alone will need 350,000 workers by 2010". As per Sengupta (2010), "Skills and knowledge are the driving forces of economic growth and social development in any country. If India can get its skill development strategy right, then it could have a skilled manpower surplus of approximately 47 million". FICCI (2012) appreciates, "This means that in the next decade, India has the potential to become a global reservoir of skilled manpower, provided it accords high priority to skill development".

\subsubsection{Building Skill Excellence for Differentiation}

For skill excellence, key components are building a skill set, growing professionally, and demonstrating performance that will optimize value in an organization. In this increasingly globalized world and the internationalized nature of the workplaces, the young students of India are found short of many skills and their chief deficiencies are identified in the areas of soft skills.

There has been an increasing awareness for the need to develop soft skills among the academia and the corporate over the past few years. Many institutions have also introduced an element of soft skills in the curricula but most of them haven't had the desired impact. One now needs to evaluate the situation and develop strategic approaches to overcome these problems without undermining the importance of technical skills.

In hierarchical organizations, functional excellence is most often the dominant driver of career success. In highly matrixed organizations and a more open culture, soft skills are essential to gaining access and acceptance in order to demonstrate the harder skill set. Global organizations most often operate with distinct cultures within their headquarters group, operating regions, and functional lines that require flexibility, sensitivity, and adjustment in order to adapt to each situation.

International Labour Conference, 97th Session Report V (2008) believes "You need to assess the culture of your organization and make sure you have the right skills to succeed and achieve differentiation".

\subsection{Bridging the Skills Gap}

Sengupta (2010) explains, "Since the enormity of the skill-gap is being felt in various sectors and at various levels, government intervention alone does not appear to be enough. To effectively bridge the huge skill-gap that exists in our country, some T\&D interventions are necessary. They could take the form of projects involving Public-Private Partnerships (PPP). PPP not only generates finances on a large scale but also provides policy, resource and infrastructure support for initiatives to impart skills training to the masses. Such projects help create a conducive environment for upscaling training. The private sector has lent its support for the establishment of the National Skill Development Corporation (NSDC) by buying a 51\% stake in it. With its capital base of Rs. 10 crore, NSDC will stimulate and coordinate initiatives in the skill development sector. The corporation's mission, 
objectives and action plan will be guided by a national policy on skill development. It will aim to improve core employability skills and competency standards, thereby creating a common platform for collaboration among private sector employers, training providers and the labour force. The government is also planning to set up a fully owned trust, the National Skill Development Fund, with a seed capital of Rs 1,000 crore".

\section{Rethinking Globalisation as a Guiding Paradigm for Change}

\subsection{Education and Training}

Sustainability requires education as an essential tool. UNESCO (2006) reports that, "People around the world recognize that current economic development trends are not sustainable and that education and training are keys to moving society towards sustainability".

\subsection{Learning Opportunities}

\subsubsection{Structured, Continuous and Time-bound Learning}

There is a fascinating finding which gets to the point that vocational educational is more valuable than traditional education though it has low or lesser perceived value among learners. Employees can be encouraged to learn on the job and they can be provided with opportunities by the organisations for continued education and development.

Time-bound learning \& application, continuous learning and applications for 'Enhanced Utility' and 'Greater Utility' of MNCs and TNCs are derived from Skills.

We have to work for a new great transformation. One has to build a culture of quality to emphasize upon excellence. As the world shrinks and best practices become known to customers, companies fight more to get the largest share of the pie. The companies need to polish people and processes in a professional manner beyond technology to create human capital. Beyond technology and processes, organizations now polish their human capital. We need qualified and experienced trainers to impart skills and teach various processes.
The workers in India should be trained for time bound learning, application \& create enhanced \& great utility culture.

The trainings for Kaizan, Six Sigma and other quality management tools are now being used to regulate the processes for the quality products in big corporations. Intelligence development of the employee has to be done on the job continuously. Traditional education needs to be clubbed with on the job training in the corporations and that will make it structured learning. Greater R\&D (Research \& Development) keeps the large corporate houses ahead of the time and competition i.e. the application of knowledge in to practice. Every hard skill needs to be inculcated through softer application by keeping the task deadlines intact. Soft application and timely demonstration of learning and utility will be the objective of the third, fourth and fifth decades of the twenty first century.

Coca Cola plant in Khurda, Orissa is a great profit making company with great utility culture. Airtel has good payments and therefore good work culture and is the world leader of GSM mobile service provider. They spend a great amount of their funds on the employee training.

Skill development can increase growth and productivity of the workforce employed in the economy which in turn is an important source for improved living standards and growth. Effective Skills development systems connect education to technical training which in turn leads them to labor market entry and labor market entry to workplace and lifelong learning. This can help countries sustain productivity growth and translate that growth into better jobs.

\subsection{Leadership}

A few insightful corporate giants like General Electric, Cisco Systems, and Intel have made advances in evolving successful global managers but still many HR leaders and senior executives continue to be disappointed with the available skills and resources.

Powell (2013) is of the belief that "Each company with its own specific needs and challenges presents a unique 
and rapidly changing landscape in which work must be accomplished. In the midst of dynamic change, it calls for an awareness of cultures as teaching new global managers how to balance corporate philosophy with the unique circumstances of the local market, is not easy. It also demands a substantial amount of independent thinking among unfamiliar surroundings. Managers with less or no experience may end up holding on to the practices they know and thus fall prey to the headquarters mentality".

\subsection{Foreign Language Capability}

Gale (2013) believes that "It may be the final blockade to corporates in universal expansion. It is a strategic imperative for companies to be able to communicate in multiple languages whether they partner with international firms, open offices abroad or simply strive to meet the needs of a diverse customer base".

\section{Further Directions}

\subsection{Create Value based Global Workforce}

Self-confidence indicates leadership which is required for navigating uncertain waters of future. We need to change the culture. The learning organisations have to be sustainable and knowledge managed. The code of working places need to shift from knowledge base to intelligence base to now value based economy. Ingham (2006) strongly emphasized that, "Corporations need to create value through people by strategic human capital management. It is more of an art than a science and is a way of leading people to unlock great business performance".

\subsubsection{Enhance Workforce Economy}

This is in terms of profits in salary of a workforce. Microsoft is considered to be the highest payers in the world. Workforce productivity holds the key to profitability. Hence there is a need to identify the parameters governing workforce productivity.

Indian companies by 2050 A.D. will be MNCs \& TNCs as one of the largest globally with the benefits of 'Demographic Dividends' and Adaptability Culture of Indians.
This will happen as we have advantage of Demographic Dividend and the adaptability culture of Indians. India \& China will drive global growth in the years to come with the rate in India projected to be up to 6-7\% between 2010 and 2013 and in China 8-8.5 \%. It will be largest in 2050 in term of PPP (Purchasing Power Parity) and also due to its all resources and soft policies which will affect global "Exchange Rate" in the economy.

MNCs from Corroborated beverages in India like Coca cola and Pepsi (U.S.) operate through 80\% Indians. Amongst Electric Goods and White Goods, LG, Samsung (South Korea) also operate through Indians. Same is the case with Pharmacy Industries like Glaxo (British), Ranbaxy (Indian), Pfizer (Swiss). In Automotive Industry like Maruti Suzuki, it has $47 \%$ Indians. So is the case with Toyota. In Industrial Machine and Manufacturing, Italian and German companies to operate through Indians. In Robotics, Japan and German TNCs like Electrical Manufacturers French A Schneider, GE too have the same way of operating. Our Indian companies like Tata, Mahindra, Bajaj, Hero, and Hyundai too have strong presence. There are some strong national companies of India like Mahindra in automotive with vertical growth and with product expansion. Another example is ITC an FMCG company with horizontal growth. FICCI (2010) emphasizes, "For the economy to grow at $8 \%$ to $9 \%$, it is required that the secondary $\&$ tertiary sectors grow at $10 \%$ to $11 \%$ assuming agriculture grows at $4 \%$. It is obvious that a large portion of the workforce would migrate from primary sector (agriculture) to secondary \& tertiary sectors. The skill sets required in the manufacturing \& service sector are quite different from those in agriculture sector. This implies that there is a skill gap when migration of this sort occurs. This means that there is a necessity for skill development in the workforce. India is expected to be a 'how to' a skilled workforce of 500 million by 2022. This would play a significant role in employment".

\subsection{Build Human Capital for Competitive Edge}

Today, human capital that represents an organization's stock of knowledge, technical skills, creativity, and experience, is becoming more and more important. 
Considering human capital as a productive asset, human capital management emerges as one of the most challenging issues for any organization. The success of the organizations, now, depends on their ability to understand how human capital related with their performance and their wealth. Corporate world in the future years will be demonstrating the improvements in quality that will spell the dictum "Employee comes first and Customer comes next". The greater goals of business will be efficiency and effective operation through cost reduction in overheads and process of production. That accomplishment can only provide the fine qualities of employee care and individual development for the purpose of 'larger human touch' in a corporate environment through professionalism.

\subsubsection{Build Global Database}

For long term success, sustainability should be the defining issue. We need to create value and for that, customer satisfaction should improve, innovation should accelerate, reputation too should go up, and efficiency should be driven through an employee. Human considered as an asset needs to be enriched to retain the talent and this can be done only if treated as the actual capital in the changing times. Human capital can be developed by training in knowledge, skills, intelligence continuously and excellently.

There has to be an increased focus from corporates. Corporations have to lead by not just vision but also by engaging people, communicating with them, educating them and giving tools to clients and suppliers. Investment value would increase by resource optimisation, both natural and human. By inspiring and supporting leaders, engaging, connecting and collaborating with stakeholders, a sustainable brand can be created while innovating and integrating.

\subsection{Assure Continuous Quality Excellence}

Companies which will survive in the market competition and consumer preferences are only those who can assure continuous quality excellence by continuous innovation and enhanced blue ocean strategy. Quality excellence assurance will turn the concept of "Customer is always right" to "Employees first and Customer next". Retention of talent and intellectual capital management by the companies will keep the organization in the fore in the race for growth.

\subsection{Create Reference Groups}

One tends to draw lasting encouragement and positive examples from people or corporations who are doing well in the business world; organizations gain public confidence and become leaders. These are the organizations which even at the time of downturn, stay aboard because of their work culture. They take great interest in people management employee discipline. There are new emerging economies and the global competitive landscape is changing dramatically. To remain competitive, companies need to decide what this means for their organization and people resource deployment. We need to have leaders, role models. This is what makes Toyota, Microsoft as our reference groups. Data from a large organization shows that using organizational reference groups extends a social network explanation of career reference selection.

Dess and Picken (1999) strongly believe that "If companies don't want to be devoured by the lions in today's knowledge-driven, competitive business arena, they must do two things--develop and retain the "best and brightest" people (their human capital), then use their other resources (financial, technological, physical, etc.) to create an organization where these people can excel. There are many organizations such as Microsoft, FedEx, Motorola, Southwest Airlines, and Citibank which recruit, develop, and retain the best available talent and design core business processes to utilize these employees' skills and talents effectively. They also facilitate individual and organizational learning, foster an environment that values cooperation, encourage risk-taking and initiative, making optimum use of technology, and more".

It is all about people management. One would want to be part of Toyota, and NASA for only its right culture. They have created culture of work, given tools and strategies to their employees to make adaptation in their lives. They empower people to interact in a positive, yet assertive way. The employees are able to figure out how to achieve a specific goal after evaluating a situation and then professionally suggest solutions that 
work well. It is a place where you attract right talent, train it, develop it and retain it. Today, organization has a market value in the form of human capital which is an important element of intellectual capital. The shift of the knowledge-based work and knowledge-based economy acceleration has made the importance of human capital increase.

Organizations which adapt human capital approach of management shift the workforce from cost to asset side of the balance sheet. It leads to people becoming assets and reasons to be invested in. Economy is the most significant motivating force behind globalization. It has a definite effect on human life. Economic power gives strength to global institutions like U.N. and I.M.F. and individual countries and societies which also empowers them to make decisions and impact decision making on world platform. Rich individuals or groups in the developed countries exert influence on decision making behind the government within their countries and at the global level, on several matters. One should adopt best practices approach to hire right employees to avoid cost later due to bad hiring decisions. Motivated, competent, well-matched employees can reinforce the backbone of the organization as they improve productivity and profitability for the entire company.

\section{Conclusion}

Considerable amount of money and time spent, both in human capital management and in the training goes wasted as in spite of this it is difficult for the corporates to keep experienced employees in the service. Even experienced managers leave after their initial commitment period. High attrition rates waste training investments and reduce effectiveness. Corporate organizations have to take some actions against these problems. Managing their human capital seems crucially important. Lots of factors as studied earlier trigger employees to leave from corporations for better cultures. So retention is a big challenge.

For sustainability, five elements of strategy, processes, people, structure and rewards also have to be closely intertwined along with internal communication and teamwork to gain competitive advantage. New learning systems need to be put in place.

This can prove possible if organisations encourage open and transparent communication and resolve their grievances and conflicts while also encouraging total personality improvement of the employees. Hard and soft skills trainings need to get enhanced for the holistic growth of the employees and the companies. To bring about the desired change, it is crucial to integrate the human resource function with communication strategies. New education policies and institutional industry interface will help. So high skills and high performance workplace model needs to be created which will be highly sustainable with greater and enhanced utility and high profitability.

\section{References}

APEC. (2010). Skills for Success in Multinational Business. Retrieved from http://hrd.apec.org/index. php/Skills_for_Success_in_Multinational_Business (Accessed 23 November 2013).

Ardichvili, A. (2012). Sustainability or limitless expansion: paradigm shift in HRD practice and teaching. European Journal of Training and Development, 36(9), 8738873.

Barney, J. (1991). Firm resources and sustained competitive advantage, Journal of Management, 17(1), 99-120.

Bartocho, E. J. K. (2016). Utilization of Human Capital Resource Capabilities as a Competitive Tool in Organizations for Improved Employee Performance in Courier Companies in Kenya. Global Journal of Human Resource Management, 4(2), 21-29.

Cable, V. (2011). Further Education and Skills System Reform Plan: Building a World Class Skills System. Retrieved fromhttps://www.gov.uk/government/uploads/ system/uploads/attachment_data/file/145452/11-1380further-education-skills-system-reform-plan.pdf

Capkovic, C. (2012). Global Bus Services Learning \& Knowledge Centre. IBM, Slovakia, Successful model of learning system in a multinational corporation. Retrieved from ieeexplore.ieee.org

Cavagnaro, E., Curiel, G. (2012), Three Levels of Sustainability, Greenleaf Publishing, Sheffield

DessGregory, G., Picken Joseph, C. (1999). Beyond Productivity: How Leading Companies Achieve 
Superior Performance by Leveraging their Human Capital. AMACOM

Docherty, P., Forslin, J., Shani, A. B. (Rami), Kira, M. (2002). Emerging work systems: From intensive to sustainable. In P. Docherty, J. Forslin and A.B. (Rami) Shani (Eds.) Creating Sustainable Work Systems: Emerging Perspectives and Practice (pp. 3-14). London: Routledge.

Elkington, J. (2006). Governance for sustainability. Corporate Governance, 14(6), 522-529.

FICCI (2010). Retrieved from http://ficci.in/ spdocument/20073/imacs.pdf

FICCI (2012). Knowledge paper on skill development in India Learner first September 2012. Retrieved fromhttp://www.ey.com/Publication/vwLUAssets/ FICCI_skill_report_2012_finalversion/\$FILE/FICCI_ skill_report_2012_finalversion_low_resolution.pdf

Gale S. F. (2013). Corporate Foreign Language Training on the Rise. Retrieved fromhttp://www.workforce.com/ articles/37-corporate-foreign-language-training-on-therise

ILO. (2010). A Skilled Workforce for Strong, Sustainable and Balanced Growth. Retrieved fromhttps://www. oecd.org/g20/summits/toronto/G20-Skills-Strategy.pdf

Ingham, J. (2006), Strategic Human Capital Management: Creating Value through People. Butterworth-Heinemann, London.

International Labour Conference. (2008) Report V - Skills for improved productivity, employment growth and development. Retrieved from http://www.ilo.org/ wcmsp5/groups/public/@ed_norm/@relconf/documents/ meetingdocument/wcms_092054.pdf

Jacobs, G., Slaus, I. (2011). Sustainability. 2011, 3, 97-154. doi: 10.3390/su3010097

Kohli, R. (2012). Growth Strategies for 2012 and Beyond. Forbes Insight Wipro Report

Porter, M. (1998). Competitive strategy: Techniques for analyzing industries and competitors. NY: The Free Press.

Powell, M. E. (2013). Soft Skills Produce Hard, Bottom Line Results [Online] Retrieved fromhttp://firstinsights. motionfirstnow.com/?p=1421
McKinsey Global Institute Report|. (June 2012). The world at work: Jobs, pay, and skills for 3.5 billion people. Retrieved from http://www.mckinsey.com/insights/ employment_and_growth/the_world_at_work (Accessed 20 June 2014)

Sengupta, D. (2010). No Skills, Only Potential. Retrieved from http://archive.outlookbusiness.com/ article_v3.aspx?artid=264961

Singh A. (2013). Achieving Sustainability through Internal Communication and Soft Skill. IUP Journal of Soft Skills, 7(1).

Terry, S. (2012). Time to turn capitalism 'inside out' roundtable report. Retrieved fromhttps://www. theguardian.com/sustainable-business/sustainabilityroundtable-interface

UNESCO. (2006). Education for Sustainable Development in Action Learning and Training Tools N1 UNESCO Education Sector. Retrieved fromhttp:// unesdoc.unesco.org/images/0015/001524/152453eo.pdf (Accessed 25 November 2013).

Warren Michael. (2009). Unwired 2.0: Green Learning for Hard Skills Training. Retrieved fromhttp:// www.humanresourcesiq.com/hr-management/articles/ unwired-2-0-green-learning-for-hard-skills-training

Wikstrom, P. (2010) 'Sustainability and organizational activities - three approaches', Sustainable Development, 18(2), 99-107. doi: 10.1002/sd.449.

\section{Authors' Profile}

Dr Sujata Dhopte is presently the Associate Professor in the Department of Economics at M K Sanghvi College of Commerce \& Economics based in Juhu, Vile Parle, Mumbai. She is also a Member, OER Team, University of Mumbai.

Meena Sinha is presently Assistant Professor - Business Communication in the Department of Management Studies at Taj Institute of Hotel ManagementAurangabad, Dr. Rafiq Zakaria Campus, Rauza Bagh, Aurangabad, Maharashtra. 
